\title{
RAPID CYCLING TYPE II BIPOLAR DISORDER
}

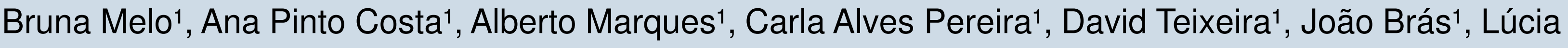 \\ Costa1, Rui Sousa', Elsa Monteiro' ${ }^{1}$ \\ 'Department of Psychiatry and Mental Health, Centro Hospitalar Tondela-Viseu, EPE., Viseu, Portugal
}

\section{Objectives}

To present a case of a Rapid Cycling type II Bipolar Disorder (RCBDII) as well as review its clinical characteristics and discuss the difficulty of its management.

\section{Background and aims:}

As initially described by Dunner \& Five (1974), and now included in the DSM 5 as a course specifier for Bipolar Disorder (BD), Rapid Cycling (RC) is a course of illness in which four or more mood episodes occur during the previous year.

Studies have failed to determine clinical characteristics that define patients with $\mathrm{RC}$ as a specific subgroup. Despite this, RC has been associated with lower response to available treatments. Although studies are still scarce, thyroid disease has been pointed out as risk factor for RC. Also, the RC resistance to lithium (a goiterogenic drug) has been linked to the development of hypothyroidism.

\section{Materials and methods:}

Patient's clinical files consultation and literature search using the search engine Pubmed $(B$ and the keywords rapid cycling bipolar disorder.

\section{Results}

\section{Clinical Case:}

- 0,56 years old

- 3 years evolution of cycling affective states between depressive states, with anhedonia, avolition, asthenia, social isolation, laboral incapacity, and states of euthymia or energy increase, each lasting about 2 to 3 weeks.

- Laboratory tests: innocent

- His medication was adjusted several times (lamotrigine, quetiapine, valproate) without ever reaching remission of symptoms or decreasing cycling frequency.

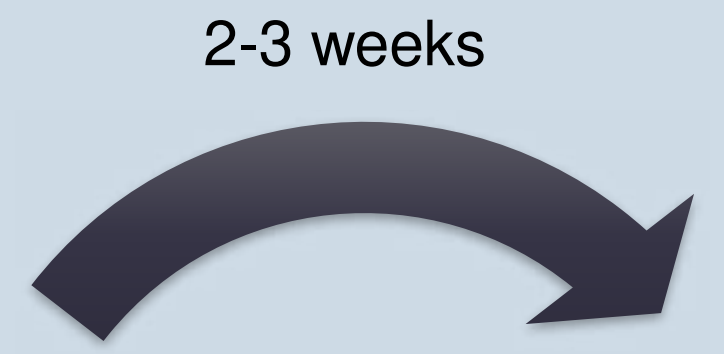

\section{Depressive States \\ Euthymia / Hyperthymia}

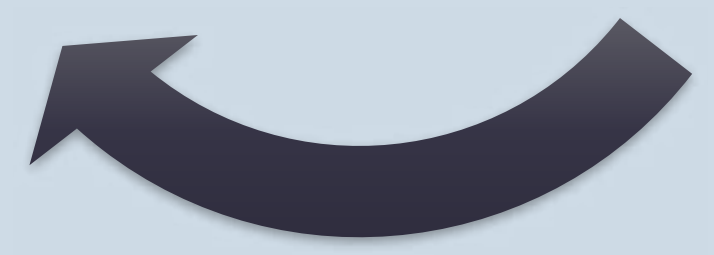

2-3 weeks

\section{Conclusions:}

$\mathrm{RC}$ is a course variant of $\mathrm{BD}$ with a poor outcome and response to treatment. Although its origin remains unknown, the impact of antidepressants use and the thyroid function must be clarified.

\section{References:}

1. Kn F, Kontis D, Gonda X, A YLN. A systematic review of the evidence on the treatment of rapid cycling bipolar disorder. 2013;(1):115-37. 2. Article R. Affective instability as rapid cycling: theoretical and clinical implications for borderline personality and bipolar spectrum disorders. 2006;1-14. A.

3. Kriiger S, Braunig F, Young L. Biological Treatment of Rapid-Cycling Bipolar Disorder. 1985;

4. Neurosciences $C$. Letter to the Editor Lamotrigine added to valproate successfully treated a case of ultra-rapid cycling. 2007;130-1.

5. Barrios C, Chaudhry TA, Goodnick PJ. Rapid cycling bipolar disorder. 2001;1963-73.

6. Bauer M, Beaulieu S, DI D, Lafer B, Rapid KR. Rapid cycling bipolar disorder - diagnostic concepts. 2008;153-62.

7. Experience C. RAPID-CYCLING BIPOLAR. 1999;22(3):585-607.

8. Ulke C, Mauche N, Makiol C, Bednasch K, Wittekind DA, Hegerl U, et al. Successful treatment in a case of ultra- rapid cycling bipolar disorder is

reflected in brain arousal regulation. 2018;1-4. 9. Bürgy M. Successful treatment of ultradian or ultra-ultra-rapid cycling : A case report. J Affect Disord [Internet]. 2011;133(3):655-6. Available from:
http://dx.doi.org/10.1016/j.jad.2011.04.052

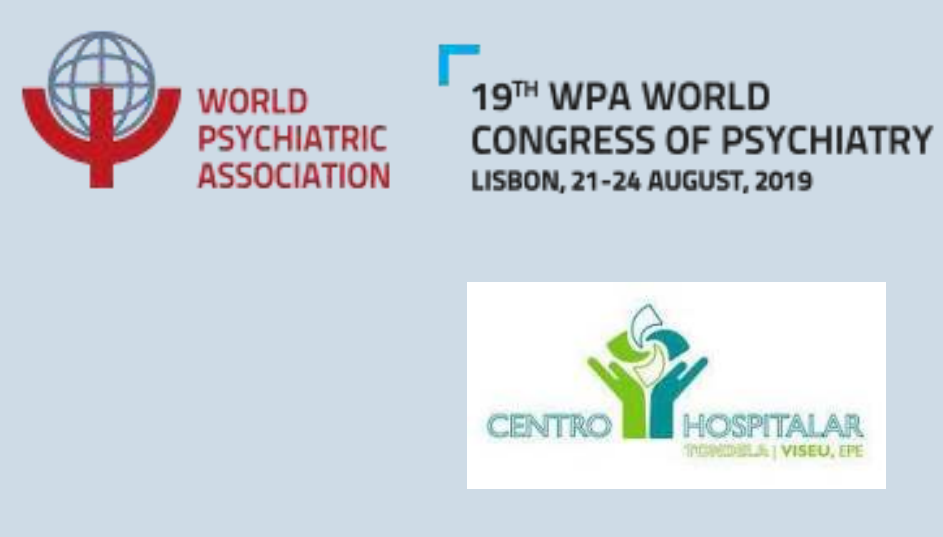

